\title{
Pulmonary atresia associated with maternal 22q11.2 deletion: possible parent of origin effect in the conotruncal anomaly face syndrome
}

\author{
Laurie H Seaver, John W Pierpont, Robert P Erickson, Richard L Donnerstein,
} Suzanne B Cassidy

\begin{abstract}
A blind study was designed to test the hypothesis that some persons with a relatively rare cardiac malformation, pulmonary atresia with ventriculoseptal defect (PA/VSD), have a recognisable phenotype. Fourteen patients with cyanotic congenital heart lesions were examined by dysmorphologists blinded to the type of cardiac malformation. Six children were judged to have a similar craniofacial appearance; all had PA/VSD. These children were not originally considered to fall within the classic phenotypes of the DiGeorge sequence or the velocardiofacial syndrome, both of which have been shown to be associated with deletions of 22 q11. More recently, 22q11 deletions have been documented in the conotruncal anomaly face syndrome and apparently isolated conotruncal heart defects. A new acronym, CATCH 22 syndrome (Cardiac defects, $A$ bnormal facies, $T$ hymic hypoplasia, Cleft palate, and Hypocalcaemia) has been suggested to encompass this very broad phenotypic spectrum. A preliminary molecular study was conducted using the dinucleotide repeat D22S264 located on chromosome 22q11.2. All cases tested with the subtle but recognisable phenotype had deletions, all lacking the maternal contribution at this locus, suggesting there may be a parent of origin effect.
\end{abstract}

Department of Pediatrics and Steele Memorial Children's Research Center, University of Arizona College of Medicine, Tucson, Arizona, USA L H Seaver

J W Pierpont

R P Erickson

$R$ L Donnerstein

S B Cassidy*

*Present address: Center for Human Genetics, Case Western Reserve University and University Hospitals of Cleveland, Cleveland, Ohio USA.

Correspondence to Dr Seaver, Greenwood Genetic Center, One Gregor Mendel Circle, Greenwood, SC 29646, USA.

Received 10 March 1994 Revised version accepted for publication 21 July 1994
( $(\mathcal{M}$ Med Genet 1994;31:830-834)

Several children with a conotruncal cardiac malformation, pulmonary atresia with ventriculoseptal defect (PA/VSD), were noted by the cardiologists caring for them to have a similar craniofacial appearance. A study by dysmorphologist examiners unaware of the type possibility that a recognisable phenotype was associated with PA/VSD. Here we report the results of this blinded clinical evaluation and a preliminary molecular study of the $22 \mathrm{q} 11.2$ region in these cases. The phenotype observed is similar to the conotruncal anomaly face (CTAF) syndrome ${ }^{1}$ which has recently been shown to be associated with a deletion within chromosome 22q11. ${ }^{2}$ We suggest that this subtle phenotype is probably under-recognised of cardiac lesion was designed to evaluate the and that the parent of origin of the deletion may be an important factor in the broad phenotypic spectrum associated with $22 \mathrm{q} 11.2$ deletions.

\section{Materials and methods}

SUBJECTS AND CLINICAL EVALUATION

Children with cyanotic congenital heart disease ranging in age from newborn to 7 years of age who had been evaluated by the Section of Pediatric Cardiology at the University of Arizona were eligible for this study, which was conducted in 1991. Those with known chromosome anomalies were excluded. The parents of 15 children with PA/VSD and 17 children with other types of heart lesions leading to cyanosis were contacted by letter to request participation in this study. Fourteen patients agreed to evaluation by the dysmorphologists, who were blinded to the specific heart lesion present. Evaluation consisted of a three to four generation pedigree, and gestational, birth, occupational, and developmental histories. Questions about potential teratogenic exposure from one month before conception throughout pregnancy were included. A standardised physical examination based on a checklist, including measurements of length or height, weight, OFC, eye distances, ear length, and hand and middle finger length, was performed, and photographs were taken.

After all patients had been evaluated, the examiners categorised them as similar with a recognisable phenotype, or not similar. At that point, chart review was performed for additional objective information including catheterisation reports, radiographs, and laboratory studies. Karyotype had been performed on two patients before our study. Chromosome analysis was not conducted in the remainder.

In 1993, patients felt to have the recognisable phenotype were recontacted for participation in a molecular study of the chromosome $22 \mathrm{q} 11.2$ region. Four families agreed to cooperate further in the study.

ISOLATION OF GENOMIC DNA FROM BLOOD

Each blood sample was frozen at $-20^{\circ} \mathrm{C}$ and then thawed. A total of $3 \mathrm{ml}$ of blood was added to $6 \mathrm{ml}$ of $1 \times \mathrm{SSC}(0.15 \mathrm{~mol} / 1 \mathrm{NaCl}$, $0.015 \mathrm{NaCitrate})$, spun at $8000 \mathrm{rpm}$ for two minutes, and the supernatant discarded. This was repeated a second time. The pellet was 

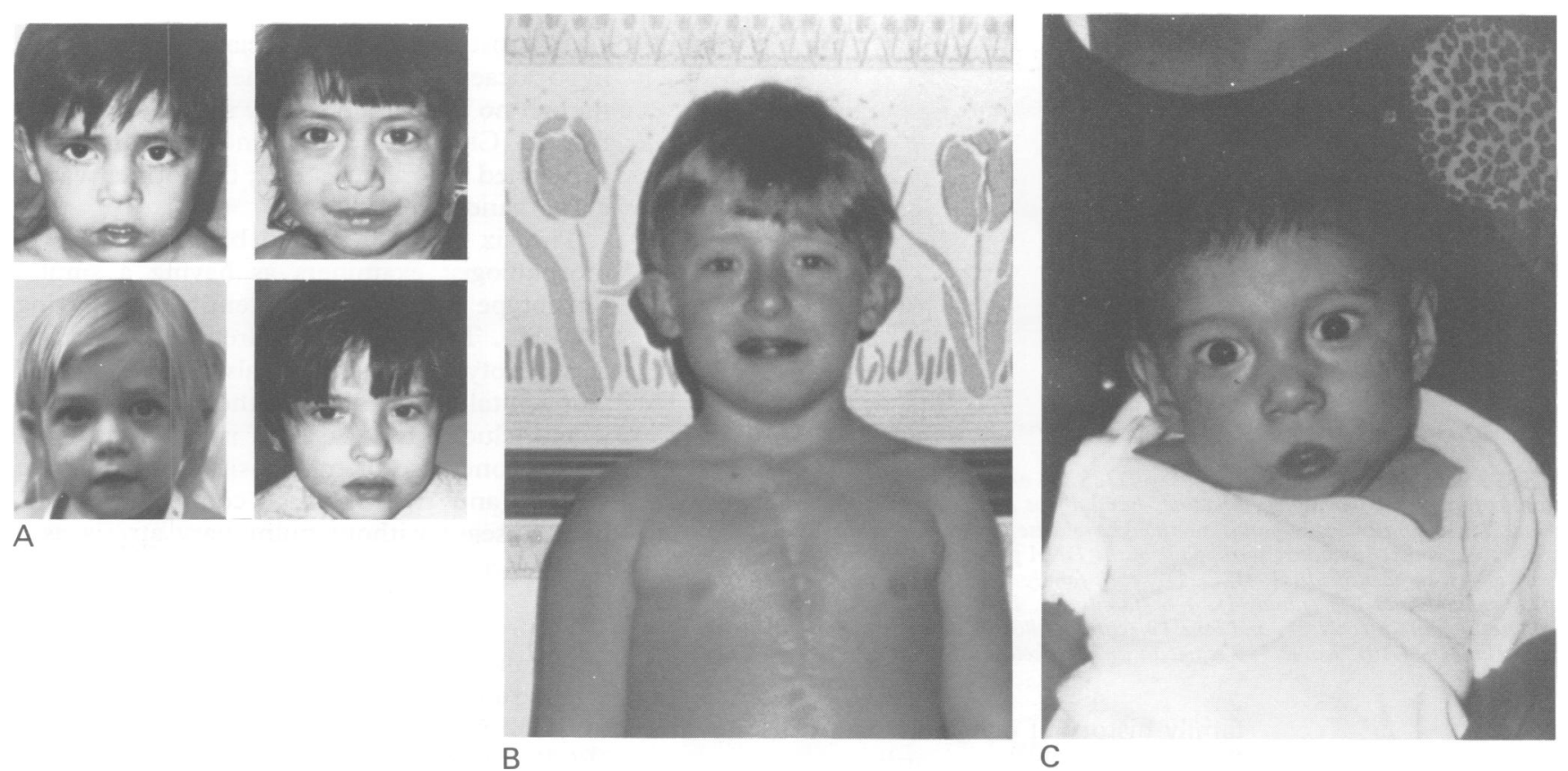

Figure 1 Six unrelated children with pulmonary atresia/ventriculoseptal defect. Note broad face, mild micrognathia, apparent hypertelorism, telecanthus, infraorbital flattening, and unusual nose. (A) Case 3 (top left), case 4 (top right), case 2 (bottom left), case 5 (bottom right); (B) case 6; (C) case 1

then resuspended in $1.6 \mathrm{ml}$ of $0.2 \mathrm{~mol} / 1 \mathrm{NaOAc}$, $\mathrm{pH} 7 \cdot 0,180 \mu \mathrm{l}$ of $10 \%$ SDS was added, and then vortexed for one to two minutes. A standard phenol/chloroform extraction was performed and the genomic DNA was then precipitated with two volumes of $\mathrm{EtOH}$. The DNA was recovered and washed with $70 \% \mathrm{EtOH}$, dried (but not fully), and dissolved in $\operatorname{ddH}_{2} \mathrm{O}$ at a concentration of approximately $0.5 \mu \mathrm{g} / \mu \mathrm{l}$.

\section{PCR REACTIONS}

PCR reactions were carried out in a total volume of $50 \mu \mathrm{l}$. Each reaction contained a final concentration of $50 \mathrm{mmol} / 1 \mathrm{KCl}, 10 \mathrm{mmol} / 1$ Tris- $\mathrm{HCl}, \mathrm{pH} 9.0$, at $25^{\circ} \mathrm{C}, 0.1 \%$ Triton X$100,1.3 \mathrm{mmol} / 1 \mathrm{MgCl}_{2}, 0.2 \mathrm{mmol} / 1 \mathrm{dNTPs}$, $1 \mu \mathrm{mol} / 1$ primer, $5 \mu \mathrm{Ci}{ }^{32} \mathrm{P}$ dCTP or dATP, and two units of Taq DNA polymerase. Two drops of mineral oil were then added to the surface of each reaction tube and the $0.5 \mathrm{ml}$ Eppendorf tubes were then heated to $75^{\circ} \mathrm{C}$ on a Techne programmable Dri-Block thermocycler. Next, $0.5 \mu \mathrm{g}$ of genomic DNA was added to each appropriately labelled tube. The tubes were

Table 1 Clinical features of six patients with PA/VSD and similar phenotype

\begin{tabular}{|c|c|c|c|c|c|c|}
\hline & \multicolumn{6}{|c|}{ Case No } \\
\hline & 1 & 2 & 3 & 4 & 5 & 6 \\
\hline Sex & $\mathbf{M}$ & $\mathbf{F}$ & $\mathbf{M}$ & $\mathrm{F}$ & $\mathrm{F}$ & $\mathbf{M}$ \\
\hline Age at evaluation & $8 \mathrm{mth}$ & $3 y$ & 3 y 2 mth & 3 y $9 \mathrm{mth}$ & 4 y $4 \mathrm{mth}$ & $6 y 9 \mathrm{mth}$ \\
\hline Stature (centile) & $<5$ th & 5 th & $<5$ th & $<5$ th & 75 th & $<5$ th \\
\hline Weight (centile) & $<<5$ th & $<5$ th & 5th & 10 th & $50-75$ th & $50-75$ th \\
\hline OFC (centile) & $<2$ nd & 5 th & 5th & 10 th & 25 th & 50 th \\
\hline \multicolumn{7}{|l|}{ Craniofacial features } \\
\hline Broad face & \pm & + & + & + & + & \pm \\
\hline Hypertelorism & $\bar{t}$ & + & + & + & + & $\overline{-}$ \\
\hline Telecanthus & + & + & + & + & + & + \\
\hline Infraorbital flattening & + & + & + & + & + & + \\
\hline Unusual nose & + & + & + & + & + & + \\
\hline Poor dentition & NA & - & - & + & + & + \\
\hline Malformed ears & - & + & + & - & - & + \\
\hline Hernia umbilical & - & + & - & - & - & + \\
\hline Hernia inguinal & + & - & + & - & - & - \\
\hline Hyperextensibility & - & + & + & + & + & - \\
\hline Long slender hands/fingers & - & + & - & - & + & - \\
\hline Mat del 22q11.2 & NT & + & NT & + & + & + \\
\hline
\end{tabular}

$\mathrm{NA}=$ not applicable. $\mathrm{NT}=$ not tested. heated to $96^{\circ} \mathrm{C}$ for two minutes and then run for 32 cycles (with the annealing temperature optimised for each primer listed below).

\section{Primer D22S264}

\section{$5^{\prime}$ ATTAACTCATAAAGGAGCCC $3^{\prime}$ $5^{\prime}$ CACCCCACCAGAGGTATTCC $3^{\prime}$}

PCR reaction conditions: $95^{\circ} \mathrm{C}$ for 1.3 minutes, $50^{\circ} \mathrm{C}$ for 1.3 minutes, $72^{\circ} \mathrm{C}$ for 1.3 minutes, and a final cycle of $72^{\circ}$ for 9.9 minutes.

Finally, $10 \mu \mathrm{l}$ of stop solution $(95 \%$ deionised formamide, $20 \mathrm{mmol} / 1 \mathrm{EDTA}$ ( $\mathrm{pH} 8.0$ ), $0.05 \%$ bromophenol blue, and $0.05 \%$ xylene cyanol FF) was added to $10 \mu$ of each sample.

\section{POLYACRYLAMIDE GEL}

A $6 \%$ polyacrylamide gel was prepared with ultrapure acrylamide and ultrapure urea using standard techniques. ${ }^{4}$ The gel was run with $1 \times$ TBE, pH $8.0 \quad(0.1 \mathrm{~mol} / 1$ TRIZMA-Base (ultrapure), $0.1 \mathrm{~mol} / 1$ boric acid, $2 \mathrm{mmol} / 1$ EDTA). The product for each locus was run against a known DNA sequence (pGEM $3 Z f+)$ as a standard molecular weight to assure appropriate allele sizes. A total of $2 \mu$ of each sample was loaded and each gel was run for 1 to 1.5 hours, dried on $0.3 \mathrm{~mm}$ Whatman paper, and exposed for one to two days on Konica PPB blue sensitive $x$ ray film.

\section{Results}

CLINICAL STUDY

Six of the 14 children evaluated by the two dysmorpholgists (LHS and SBC) were determined to have a similar phenotype. There were three males and three females among the similar cases, who ranged from 8 months to 6 years of age. Four of six were Mexican or Mexican-American and two were American whites. We found no common potential teratogenic exposure. One case had a positive 


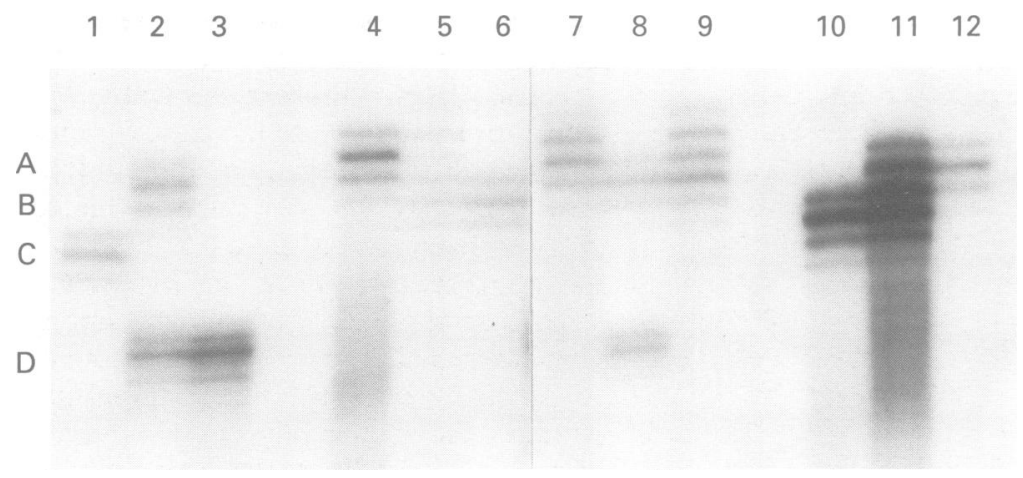

Figure 2 Results of PCR analysis using D22S264 on chromosome 22q11.2. The major band is flanked by one lighter "shadow" band above and one or two "shadow" bands below. These light intensity bands are thought to arise in the PCR reaction as multiples of two (repeat units) secondary to slippage of the DNA polymerase during amplification. Four alleles are identified $(A, B, C, D)$, each family is loaded mother-father-patient from left to right. Lanes 1-3 (family I), 4-6 (family II), 10-12 (family III). Subjects in lane 3 (case 2), lane 6 (case 5), and lane 12 (case 4) show no contribution of a maternal allele (lanes 1,4,10). Lanes 7-9 represent an unaffected control family.

family history of congenital heart disease in a first cousin with dextrocardia.

Specific features of this subtle but recognisable phenotype are illustrated in fig 1 and include a broad face, absolute or relative hypertelorism or telecanthus or both, infraorbital flattening, and an unusual nose with deeply grooved nasal alae creating a prominent nasal tip. None had the nasal appearance typical of the velocardiofacial (VCF) syndrome. ${ }^{5-7}$ All six cases had normal birth weight and length. Mild postnatal growth deficiency (defined as weight or height less than the 5th centile) was present in five out of six. Microcephaly was present in one case, an 8 month old, who had severe failure to thrive and had spent the majority of his life in hospital. The three oldest children had abnormal dentition with numerous caries and capped teeth. Three cases had unusual or overfolded helices, including one case with prominent cupped ears. Two cases had umbilical hernias and two had repaired inguinal hernias. Four of the six cases had moderately hyperextensible large joints. Two cases had long, slender hands. Case 2 had postaxial polydactyly, a trait she shared with her mother, who was otherwise phenotypically normal. These results are summarised in table 1 .

Development was assessed by parental recall of milestones and clinical examination. Gross motor delay was common; the mean age for walking unassisted was 17 months (range 14 to 22 months). The youngest, case 1 , who is microcephalic does not yet roll over or sit, and he vocalises but does not babble at the age of 8 months. Language development was reported as a strength in two patients (cases 4 and 6). Language acquisition was reported as normal in cases 3 and 5 , but articulation difficulty in case 5 made her speech difficult to understand. Case 2 suffered a postoperative left hemispheric stroke at 15 months, with residual language impairment and mild right hemiplegia. By the age of 26 months she had two word sentences in both sign language and with speech. None of the patients was considered to have hypernasal speech.

There was no history of seizures (except in case 2 postoperatively, associated with stroke), hypocalcaemia, or immune deficiency, although no formal laboratory studies were performed. Cases 3 and 6 had normal karyotypes performed before our study; the former was at a 700 band level.

The six children judged blind by the dysmorphologist examiners as having a similar phenotype were all later identified as having PA/VSD. Three other children, not classified as phenotypically similar, also had PA/VSD. Congenital heart lesions in the remaining subjects included two cases of isolated tricuspid atresia, one case of transposition of the great vessels, and two cases of complex cyanotic heart disease without pulmonary atresia as a component.

\section{MOLECULAR STUDY}

The results of molecular analysis of the region 22q11.2 using the polymerase chain reaction (PCR) and the dinucleotide repeat, D22S264, are shown in fig 2 and summarised in table 2 . Four families out of six agreed to participate and were tested. All children showed a maternal deletion at this locus. Three out of four mothers are apparently homozygous. In two of these cases, maternal grandparents were available for study, with results that could be consistent with maternal homozygosity. All of the mothers were phenotypically normal, with no signs or symptoms to suggest that they were hemizygous.

\section{Discussion}

The results of this blind study confirmed a subtle but recognisable phenotype associated with PA/VSD in six of nine cases examined with this relatively rare heart lesion. The phenotype is not considered to be typical of VCF syndrome, as it was originally described. The phenotype was not noted in five other children with other cyanotic heart lesions.

Fifteen cases of PA/VSD were reported by Jedele $e t a l^{8}$ in 1992 as cases of the VCF

Table 2 Results of PCR using microsatellite D22S264

\begin{tabular}{|c|c|c|c|c|}
\hline & \multicolumn{4}{|l|}{ Alleles } \\
\hline & $A$ & $B$ & $C$ & $D$ \\
\hline $\begin{array}{l}\text { Negative } \\
\text { control }\end{array}$ & - & - & - & - \\
\hline $\begin{array}{l}\mathrm{I} \cdot 1 \mathrm{a}(\mathrm{mGM}) \\
\mathrm{I} \cdot 1 \mathrm{~b}(\mathrm{mGF}) \\
\mathrm{I} \cdot 1 \mathrm{c}(\mathrm{M}) \\
\mathrm{I} \cdot 2(\mathrm{~F}) \\
\mathrm{I} \cdot 3(\mathrm{pt})\end{array}$ & $\begin{array}{l}- \\
- \\
- \\
-\end{array}$ & $\begin{array}{l}+ \\
+ \\
+ \\
+\end{array}$ & $\begin{array}{l}+ \\
+ \\
+1+ \\
- \\
-\end{array}$ & $\begin{array}{l}- \\
\overline{-} \\
+ \\
+\end{array}$ \\
\hline $\begin{array}{l}\mathrm{II} \cdot 1(\mathrm{M}) \\
\mathrm{II} \cdot 2(\mathrm{~F}) \\
\mathrm{II} \cdot 3(\mathrm{pt})\end{array}$ & $\begin{array}{l}+1+ \\
+ \\
-\end{array}$ & $\begin{array}{l}- \\
+ \\
+\end{array}$ & $\begin{array}{l}- \\
- \\
-\end{array}$ & - \\
\hline $\begin{array}{l}\text { III } \cdot 1 \mathrm{a}(\mathrm{mGM}) \\
\text { III } \cdot 1 \mathrm{~b}(\mathrm{mGF}) \\
\text { III } \cdot 1 \mathrm{c}(\mathrm{M}) \\
\text { III } \cdot 2 \text { (F) } \\
\text { III } \cdot 3 \text { (pt) }\end{array}$ & $\begin{array}{l}- \\
+ \\
+ \\
+\end{array}$ & $\begin{array}{l}+ \\
+ \\
+1+ \\
+ \\
-\end{array}$ & $\begin{array}{l}- \\
\overline{-} \\
- \\
-\end{array}$ & $\begin{array}{l}+ \\
- \\
- \\
-\end{array}$ \\
\hline $\begin{array}{l}\text { IV·1 }(\mathrm{M}) \\
\text { IV·2 (F) } \\
\text { IV } 3(\mathrm{pt})\end{array}$ & $\begin{array}{l}- \\
+1+ \\
+\end{array}$ & $\begin{array}{l}+ \\
- \\
-\end{array}$ & $\begin{array}{l}\overline{-} \\
-\end{array}$ & $\begin{array}{l}+ \\
-\end{array}$ \\
\hline
\end{tabular}

Four alleles (A, B, C, D) are identified. Patients $1 \cdot 3, \mathrm{II} \cdot 3, \mathrm{III} \cdot 3$, and IV 3 all show a maternal deletion; however, paternal disomy cannot be ruled out.

$+=$ allele present, $-=$ allele absent,$+1+=$ homozyous, $\mathrm{mGM}=$ maternal grandmother, $\mathrm{mGF}=$ maternal grandfather, $\mathrm{M}=$ mother, $\mathrm{F}=$ father, $\mathrm{pt}=$ patient. 
syndrome. The age range in that study (3 months to $7 \frac{1}{2}$ years) was similar to ours. Ten of their 15 patients had palatal defects including velopharyngeal incompetence and 10/15 were reported to have hypernasal speech. A typical facial appearance was noted, as were minor ear and hand anomalies. Most of the older children had excessive and severe dental caries. There were two cases of hypocalcaemia but no other apparent features of the DiGeorge sequence. The authors suggested that PA/VSD may particularly be associated with the VCF syndrome. A photograph of one of the younger children (case 14, 9 months) shows a subtle facial phenotype similar to the one we describe. This child was not noted to have a palatal defect and was too young to assess speech.

Conotruncal anomaly face syndrome, originally reported in a Japanese publication, ${ }^{1}$ is characterised by cardiac outflow tract defects, a characteristic facial appearance including hypertelorism, cleft soft palate or nasal voice, malformed ears, and mild mental retardation. At least $50 \%$ of the cases were considered by Goldberg $e t$ al ${ }^{7}$ to fall within the VCF spectrum. Fourteen of 37 cases (39\%) of CTAF syndrome reported had TOF with PA. ${ }^{9}$ CTAF syndrome has recently been shown to be associated with deletion of $22 \mathrm{q} 11$ by fluorescence in situ hybridisation (FISH). ${ }^{2}$ Of interest, all five cases tested had TOF with PA.

Before 1991, nearly all cases of VCF syndrome were ascertained through cleft palate, velopharyngeal incompetence, or hypernasal speech $^{7}$ and a very consistent craniofacial and developmental phenotype was described. ${ }^{5-71011}$ In 1992, the molecular basis for the VCF syndrome was discovered to be microdeletion of a gene, or more likely genes, located on chromosome 22q11.2. ${ }^{1213}$ The spectrum of the VCF syndrome has now been expanded to include probably all familial and some sporadic cases of the DiGeorge sequence (DGS), ${ }^{14}$ some cases of Robin sequence, ${ }^{6}$ and a very wide spectrum of severity. ${ }^{71516}$ The acronym CATCH 22 syndrome (Cardiac defects, $A$ bnormal facies, Thymic hypoplasia, $C$ left palate, Hypocalcaemia) has been suggested to describe this now very broad clinical spectrum of conditions associated with $22 \mathrm{q} 11$ deletions. ${ }^{17}$ To date, no molecular difference has been found to account for the phenotypic variability of the VCF syndrome, ${ }^{1213}$ although it has been postulated that deletions of different loci may correlate with specific defects such as cleft palate, congenital heart disease, and thymic hypoplasia. ${ }^{12}$ Intra- and interfamilial variability may ultimately be explained by variation in genetic background, in utero environment, ${ }^{1218}$ modifying genes, unstable mutations, ${ }^{19}$ and possibly a parent of origin effect, as the majority of familial cases have been maternally transmitted. ${ }^{920}$ Polymorphic short tandem repeats (STRPs) are currently being used by one group to screen at risk patients before more cumbersome techniques such as dosage analysis, and FISH which does not provide parent of origin information. ${ }^{21}$

Features we describe in our study are consistent with those previously reported in the
CTAF syndrome ${ }^{129}$ and the study by Jedele $e t$ $a l,{ }^{8}$ and include short stature, developmental delay, typical facial appearance with hypertelorism, unusual nose, dental caries, minor ear anomalies, and long slender fingers. It is interesting that only one child we evaluated (case 5) was considered to have mild articulation difficulty and none had hypernasal speech or a palatal defect. This may be simply because of the small number of patients enrolled in our study, but illustrates an important point; without this feature, these children had subtle craniofacial findings that may not be recognised, and thus they may not be referred for further genetic diagnosis or study. The mild motor delay evident in our study was not especially concerning the parents considering the significant heart disease, admissions to hospital, and procedures their children had undergone. The growth deficiency (except case 1) was also relatively mild. It is not clear whether the children in our study will "evolve" over time into a more typical VCF syndrome appearance. However, in one published adult case with CTAF syndrome associated with the deletion, the authors were not certain that he fitted the dysmorphological diagnosis, but considered photographs taken as a child to be more consistent. ${ }^{2}$ This suggests that the facial appearance can become even more subtle over time instead of more "typical" of the VCF syndrome.

The molecular study of four of our cases showed a maternal deletion of chromosome $22 \mathrm{q} 11.2$, in each case tested using the dinucleotide repeat, D22S264. ${ }^{3} \mathrm{D} 22 \mathrm{~S} 264$ is estimated to be approximately $2 \mathrm{Mb}$ distal to D22S75 (N25), the most proximal probe used within the DiGeorge critical region (DGCR), which has been estimated to extend over a minimum interval of $750 \mathrm{~kb} .{ }^{12}{ }^{13}$ All CTAF syndrome cases tested so far have PA and are deleted using FISH within the DGCR. ${ }^{2}$ These findings suggest that (1) TOF with PA may particularly be associated with a subtle phenotype that may not be immediately recognisable as falling within the VCF spectrum; (2) TOF with PA may be frequently associated with deletion of $22 \mathrm{q} 11.2$; (3) the extent of the deletion may be large, extending at least $1 \mathrm{Mb}$ distal to $\mathrm{N} 25$; and (4) D22S264 is a useful polymorphic probe and has enabled us to determine the maternal origin of the deletion in the four cases tested, additionally suggesting that there may be a parent of origin effect, or an imprinted locus in this region.

It is yet to be determined whether all patients with 22q11 deletions have the same natural history and risk for complications including speech delay (if they do not have a palatal defect), learning disabilities, or psychiatric illness. ${ }^{22}$ This becomes increasingly important as more of these patients are identified in infancy and in utero. ${ }^{18}$ While the term CATCH 22 syndrome may be a useful mnemonic for remembering important features, it may not be useful for the clinician called upon to counsel these families until further clinical and molecular correlation is available. 
1 Kinouchi A, Mori K, Ando M, Takao A. Facial appearance of patients with conotruncal anomalies. Pediatr fapan of patients

2 Burn J, Takao A, Wilson D, et al. Conotruncal anomaly face syndrome is associated with a deletion within chromosome 22q11. ₹ Med Genet 1993;30:822-4.

3 Marineau C, Aubry M, Julien JP, Rouleau GA. Dinucleotide repeat polymorphism at the D22S264 locus. Nucleic Acids repeat polymorphism

4 Sambrook J, Fritsch EF, Maniatis T. Molecular cloning. A laboratory manual. 2nd ed. Cold Spring Harbor, New York: Cold Spring Harbor Laboratory Press, 1989:13.45-13.53.

5 Shprintzen RJ, Goldberg RB, Lewin ML, et al. A new syndrome involving cleft palate, cardiac anomalies, typical facies, and learning disabilities: velo-cardio-facial syndrome. Clefi Palate ₹ 1978;15:56-62.

6 Shprintzen RJ, Goldberg RB, Young D, Wolford L. The velo-cardio-facial syndrome: a clinical and genetic analysis. Pediatrics 1981;67:167-72.

7 Goldberg R, Motzkin B, Marion R, Scambler PJ, Shprintzen RI. Velo-cardio-facial syndrome: a review of 120 patients. Am 7 Med Genet 1993;45:313-19.

8 Jedele KB, Michels VV, Puga FJ, Feldt RH. Velo-cardiofacial syndrome associated with ventricular septal defect, pulmonary atresia, and hypoplastic pulmonary arteries. pulmonary atresia, and hyp

9 Takao A, Terai M, Ando $\dot{M}$, Momma K. Cardiovascular malformations in the conotruncal anomaly face syndrome. In: Doyle EF, Engle MA, Gersony WM, et al, eds. Pediatric candiology. Proceedings of the Second World Congress. New York: Springer-Verlag, 1985:926-8.

10 Arvystas M, Shprintzen RJ, Craniofacial morphology in the velo-cardio-facial syndrome. I Craniofac Genet Dev Biol 1984;4:39-45.

11 Golding-Kushner KJ, Weller G, Shprintzen RJ. Velo-cardiofacial syndrome: language and psychological profiles. $\mathcal{f}$ Craniofac Genet Dev Biol 1985;5:259-66.
12 Driscoll DA, Spinner NB, Budarf ML, et al. Deletions and microdeletions of 22q11.2 in velo-cardio-facial syndrome. Am $\mathcal{7}$ Med Genet 1992;44:261-8.

13 Kelly D, Goldberg R, Wilson D, et al. Confirmation that the velo-cardio-facial syndrome is associated with haploinsufficiency of genes at chromosome $22 \mathrm{q} 11$. Am $\mathcal{F} \mathrm{Med}$ insufficiency of genes a

14 Stevens CA, Carey JC, Shigeoka AO. DiGeorge anomaly and velocardiofacial syndrome. Pediatrics 1990;85:526-30.

15 Beemer FA, deNef JJEM, Delleman JW, Bleeker-Wagemakers EM, Shprintzen RJ. Additional eye findings in a girl with the velo-cardio-facial syndrome. Am $\mathcal{F}$ Med Genet 1986;24:541-2.

16 Meinecke P, Beemer FA, Schinzel A, Kushnick T. The velocardio-facial (Shprintzen) syndrome. Eur $\mathcal{F}$ Pediatr 1986; 145:539-44.

17 Wilson DI, Burn J, Scambler P, Goodship J. DiGeorge syndrome: part of CATCH 22. ₹ Med Genet 1993;30: 852-6.

18 Driscoll DA, Salvin J, Sellinger B, et al. Prevalence of 22q11 microdeletions in DiGeorge and velocardiofacial syndromes: implications for genetic counseling and prenatal diagnosis. F Med Genet 1993;30:813-17.

19 Holder SE, Winter RM, Kamath S, Scambler PJ. Velocardiofacial syndrome in a mother and daughter: varielocardiofacialsyndrome in a mother and daugh 1993.30 : ability

20 Wilson DI, Goodship JA, Burn J, Cross IE, Scambler PJ. Deletions within chromosome 22q11 in familial congenital Deletions within chromosome 22q11 in

21 Gorman GN, Buetow KH, Dugan D, Budarf ML, Emanuel BS, Driscoll DA. Isolation of poly-TG markers in the DiGeorge critical region (DGCR). Am f Hum Genet 1993; 53:184A.

22 Shprintzen RJ, Goldberg R, Golding-Kushner KJ, Marion RW. Late-onset psychosis in the velo-cardio-facial syndrome. Am f Med Genet 1992;42:141-2. 